\title{
GAMBARAN MOTIVASI INTRINSIK DAN EKSTRINSIK MASYARAKAT DALAM PEMAKAIAN GIGI TIRUAN DI DESA MUARA BAHAN KABUPATEN KUANTAN SINGINGI
}

\author{
Jihan Natassa'), Yeyen Gumayesty ${ }^{2)}$, Raviola ${ }^{3)}$ \\ ${ }^{1}$ STIKes Hang Tuah Pekanbaru \\ Email : jihannatassa@yahoo.co.id \\ 2 STIKes Hang Tuah Pekanbaru \\ yeyenrangkuti@gmail.com \\ ${ }^{3}$ STIKes Hang Tuah Pekanbaru \\ raviola@yahoo.com
}

\begin{abstract}
In making decisions to use dentures, motivation factors play a very large role. Some people use denture due to extrinsic motivation and partly due to instristic motivation. The purpose of this study is to know the description of community motivation in the use of dentures in Muara Bahan Village, Kuantan Singingi Regency 2018. This type of research is quantitative descriptive. The study was conducted in Muara Bahan village, Kuantan Singingi Regency in the month of February-August 2018. The population in this study were all communities in Hamlet III Muara Bahan Village Kuantan Singingi Regency with a population of 2936 people with a sample of 97 respondents. The sampling technique in this study used a stratified sampling technique. The results of the study showed the majority of respondents who used denture were as many as 58 respondents (59.9\%) while the respondents who had used denture were 39 respondents (40.2\%), the majority of respondents' needs in the use of high dentures were 82 respondents $(84,5 \%)$ while respondents with low needs were 15 respondents (15.5\%). the majority have positive perceptions, amounting to 93 respondents (95.9\%) while respondents who have a negative perception are 4 respondents $(4.1 \%)$. the majority are knowledgeable, amounting to 88 respondents (90.7\%) while respondents with low knowledge are 9 respondents $(9.3 \%)$. the majority said there was no service for making complete dentures which amounted to 96 respondents (99.0\%) while respondents who said there was a service for making dentures that had complete facilities totaling 1 respondent (1.0\%). It could be concluded that the majority of respondents used denture, has a positive perception and is highly knowledgeable. Expected users of dentures maintain dental and oral health and can pay attention to the effects of tooth loss.
\end{abstract}

keywords $\quad$ : Intrinsic Motivation and Community Extrinsics, Use of Dentures

\section{ABSTRAK}

Dalam pengambilan keputusanuntuk menggunakan gigi tiruan, faktor motivasi memegang peranan yang sangat besar. Sebagian masyarakatmemakai gigi tiruan disebabkan motivasi ekstrinsik dan sebagian lagi disebabkan motivasi instristik.Tujuan dari penelitian ini adalah untuk diketahuinya gambaran motivasi masyarakat dalam pemakaian gigi tiruan di Desa Muara Bahan Kabupaten Kuantan Singingi Tahun 2018. Jenis penelitian ini kuantitatif yang bersifat deskriptif. Penelitian dilaksanakan di desa muara Bahan Kabupaten Kuantan Singingi pada bulam Februari-Agustus2018. Populasi dalam penelitian ini adalah seluruh masyarakat di Dusun III Desa Muara Bahan Kabupaten Kuantan Singingi dengan jumlah populasi 2936 orangdengansampel 97 responden. Teknik sampling dalam penelitian ini menggunakan teknik stratified sampling (proportional sampling). Hasilpenelitianmenunjukanmayoritas responden yang menggunakan gigi tiruan yaitu sebanyak 58 responden $(59,9 \%)$ sedangkan responden yang pernah menggunakan gigi tiruan sebanyak 39 responden $(40,2 \%)$, mayoritas kebutuhan responden dalam pemakaian gigi tiruan tinggi yaitu berjumlah 82 responden $(84,5 \%)$ sedangkan responden yang berkebutuhan rendah berjumlah 15 responden $(15,5 \%)$. mayoritas berpersepsi positif yaitu berjumlah 93 responden $(95,9 \%)$ sedangkan responden yang berpersepsi negatif berjumlah 4 responden (4,1\%).mayoritas berpengetahuan tinggi yaitu berjumlah 88 responden (90,7\%) sedangkan responden yang berpengetahuan rendah berjumlah 9 responden $(9,3 \%)$.mayoritas mengatakan tidak ada pelayanan pembuatan gigi tiruan yang lengkap yaitu berjumlah 96 
responden $(99,0 \%)$ sedangkan responden yang mengatakan ada pelayanan pembuatan gigi tiruan yang memiliki fasilitas lengkap berjumlah 1 responden $(1,0 \%)$ Dapat disimpulkan bahwa mayoritas responden memakai gigi tiruan, berpresepsi positif dan berpengetahuan tinggi. Diharapkan pengguna gigi tiruan menjaga kesehatan gigi dan mulut dan dapat memperhatikan dampak dari kehilangan gigi.

Kata Kunci : Motivasi Intrinsik dan Ekstrinsik Masyarakat, Pemakaian Gigi Tiruan

\section{PENDAHULUAN}

Gigi tiruan adalah ilmu dan seni pembuatan suatu pengantian yang padan (sesuai) bagi hilangnya bagian koronal gigi, satu atau lebih gigi yang hilang serta jaringan sekitarnya, agar supaya fungsi, penampilan rasa nyaman dan kesehatan yang terganggu karenanya dapat di pulihkan. Walaupun disepakati bahwa geligi bukanlah bagian tubuh terpenting untuk mempertahankan hidup, banyak orang menganggap bahwa jumlah gigi akan membantu mereka mengunyah makanan dengan mudah (Haryanto, 1991).

Gigi tiruan terbagi atas 3 macam gigi tiruan yaitu, gigi tiruan sebagian lepasan, gigi tituan lengkap lepasan dan gigi tiruan cekat ( crown \& bridge). Kehilangan gigi sangat berpengaruh terhadap kesehatan gigi dan mulut, kehilangan gigi dapat mengakibatkan erupsi berlebih, terganggunya kebersihan mulut, Penurunan Efisiensi Kunyah, kelainan bicara dan dan memburuknya penampilan (Haryanto, 1991).

Dalam pengambilan keputusan seseoranguntuk menggunakan gigi tiruan, faktor motivasi dapat memegang peranan yang sangat besardalamkeputusanini. Sebelum seseorang memutuskan menggunakan gigi tiruan, sudah pasti setiap individu memiliki motivasi yang ia harapkan akan tercapai setelah penggunaan gigi tiruan tersebut (Nira, 2011)

\section{Riset Kesehatan Dasar (RISKESDAS)} Departemen Kesehatan Republik Indonesia tahun 2013, melaporkan bahwa prevalensi nasional kesehatan gigi dan mulut adalah 25,9 persen, sebanyak 14 provinsi mempunyai pravelensi masalah gigi dan mulut diatas angka nasional. Secara keseluruhan kemampuan untuk mendapatkan pelayanan dari tenaga medis gigi sebesar 8,1 persen (EMD). Ditemukan EMD (Effective Medical Demand) meningkat pada kelompok umur yang lebih tinggi, umur 45-54 tahun meningkat (EMD: 10,6 dibanding Emd umur 12 tahun: 7,0), EMD diperkirakan $(8,6)$ lebih besar dari EMD pedesaan $(7,5)$ dan EMD meningkat pada status ekonomi lebih tinggi (EMD teratas: 9,0). Prevalensi nasional menyikat gigi setiap hari adalah 94,2 persen sebanyak 15 provinsi berada dibawah prevalensi nasional.

Pelayanan kesehatan gigi dan mulut di Provinsi Riau tahun 2017 menyatakan bahwa pencabutan gigi tetap berjumlah 19.886 orang dan 5,694 orang yang menerima perawatan tumpatan gigi tetap yang terbagi dari 12 kabupaten di seluruh Provinsi Riau. Di daerah kuantan singinggi terdapat pelayanan kesehatan gigi dan mulut berupa tumpatan gigi tetap berjumlah 331 orang dan pencabutan gigi tetap berjumlah 824 orang. Berdasarkan data tersebut dapat dilihat bahwa di daerah kuantan singingi terdapat banyak masyarakat yang kehilangan gigi nya, dan peranan motivasi memberikan nilai penting basi masyarakat yang menggunakan gigi tiruan, baik itu motivasi dari diri seseorang itu atau motivasi yang diberikan oleh orang lain.

Berdasarkan penelitian Nurwahid dkk, dalam penelitian sebelumnya menyatakan bahwa sebagian besar masyarakatkelurahan batu kota pemakai gigi tiruan memiliki motivasi ekstrinsik dalam kategori sedang, sumber motivasi terbesar bagi responden diperoleh dari media cetak, online, hingga media internet.

Sukini dkk (2015) sebelumnya mengatakan bahwa penyebab terbanyak motivasi internal lansia terhadap pemakaian gigi tiruan ada pada perasaan terganggunya pengunyahan karena ada gigi yang hilang dan adanya kepercayaan bahwa dengan memakai gigi tiruan akan bisa mengatasi hambatan yang muncul sebelum memakai gigi tiruan. Kontribusi terbesar dari motivasi eksternal lansia terhadap pemakaian gigi tiruan ada pada adanya kepedulian lingkungan terhadap kesehatan 
dimana lansia tinggal, Orang memiliki kecenderungan mengikuti trend yang ada dilingkungannya.

Desa muara bahan terletak di kabupaten kuantan singingi kecamatan singingi hilir dengan jumlah masyarakat 2936 orang yang terbagi atas 4 dusun terdiri dari 21 RT. Pada survei awal dilakukan wawancara kepada beberapa masyarakat yang menggunakan gigi tiruan mereka mengatakan bahwa mereka termotivasi untuk menggunakan gigi tiruan dengan tujuan untuk memberikan rasa percaya diri mereka karena kehilangan gigi aslinya dan gigi tiuan bisa digunakan dalam jangka waktu yang ckup lama. Ada juga masyarakat yang pada awalnya merasa ragu untuk menggunakan gigi tiruan karena kurangnya motivasi mereka terhadap gigi tiruan tersebut, mereka mengatakan jika ingin membuat gigi tiruan mereka harus menempuh jarak yang terbilang jauh dan biaya yang tidak sedikit.

Berdasarkan penelitian-penelitian yang sudah ada motivasi memberikan pengaruh besar bagi masyarakat dalam penggunaan gigi tiruan. Oleh karena itu penulis tertarik untuk melakukan penelitian mengenai gambaran motivasi intrinsik dan ekstrinsik masyarakat dalam pemakaian gigi tiruan di desa muara bahan kabupaten kuantan singingi tahun 2018.Tujuandaripenelitianiniadalahuntuk diketahuinya gambaran motivasi masyarakat dalam pemakaian gigi tiruan di Desa Muara Bahan Kabupaten Kuantan Singingi Tahun 2018.

\section{METODE}

Jenis penelitian ini kuantitatifyang bersifat deskriptif untuk mengetahui gambaran motivasi internal dan eksternal masyarakat dalam pemakaian gigi tiruan di Desa Muara Bahan Kabupaten Kuantan Singingi. Penelitian dilaksanakan di desa muara Bahan Kabupaten Kuantan Singingi pada bulam FebruariAgustus2018. Populasi dalam penelitian ini adalah seluruh masyarakat di Dusun III Desa Muara Bahan Kabupaten Kuantan Singingi dengan jumlah populasi 2936 orangdengansampel 97 responden. Teknik sampling dalam penelitian ini menggunakan teknik stratified sampling (proportional sampling). Pengambilan secara proporsi dilakukan dengan mengambil subyek dari seriap dusun ditentukan seimbang dengan banyaknya subyek dalam masing-masing dusun di Desa Muara

\section{Hasil}

\section{Karakteristik Responden}

Karakteristik responden digunakan untuk mengetahui keragaman responden berdasarkan umur, jenis kelamin, pendidikan, dan pekerjaan. Hal tersebut diharapkan dapat memberikan gambaran yang cukup jelas mengenai kondisi dari responden dan kaitannya dengan masalah dan tujuan penelitian.

Tabel 1

Distribusi Frekuensi Karakteristik Responden Berdasarkan Umur, Jenis Kelamin, Pendidikan, Pekerjaan Di Desa Muara Bahan Kabupaten Kuantan Singingi Tahun 2018

\begin{tabular}{|c|c|c|c|}
\hline No & Variabel & Jumlah & $\begin{array}{c}\text { Presentase } \\
(\%)\end{array}$ \\
\hline \multirow[t]{5}{*}{1} & Umur & & \\
\hline & $-20-25$ & 15 & 15,5 \\
\hline & $-26-35$ & 54 & 55,7 \\
\hline & $-36-40$ & 28 & 28,9 \\
\hline & Total & 97 & 100 \\
\hline \multirow[t]{4}{*}{2} & Jenis Kelamin & & \\
\hline & - Perempuan & 47 & 48,5 \\
\hline & - Laki-Laki & 50 & 51,5 \\
\hline & Total & 97 & 100,0 \\
\hline \multirow{7}{*}{3} & Pendidikan & & \\
\hline & - Tidak & 5 & 5,2 \\
\hline & Sekolah & 24 & 24,7 \\
\hline & - SD & 25 & 25,8 \\
\hline & - SMP & 30 & 30,9 \\
\hline & $\begin{array}{l}\text { - SMA } \\
\text { - PT }\end{array}$ & 13 & 13,4 \\
\hline & Total & 97 & 100,0 \\
\hline \multirow[t]{5}{*}{4} & Pekerjaan & & \\
\hline & - Petani & 43 & 44,3 \\
\hline & - IRT & 33 & 34,0 \\
\hline & - Swasta & 21 & 21,6 \\
\hline & Total & 97 & 100,0 \\
\hline
\end{tabular}

Berdasarkan tabel 1 dapat dilihat sebagian besar responden berumurdewasa awal 26-35 tahun sebanyak 54 orang $(55,7 \%)$, responden berjenis kelamin laki-laki 50 orang $(51,5 \%)$, responden yang berpendidikan SMA sebanyak 30 orang $(30,9 \%)$ dan responden mayoritas berprofesi sebagai petani berjumlah 43 orang $(44,3 \%)$ 


\section{Analisis Univariat}

\section{a. Gigi Tiruan}

Gambaran masyarakat di desa muara bahan yang menggunakan gigi tiruan dan pernah menggunakan gigi tiruan yang berjumlah 97 orang dapat dilihat pada tabel 4.4 dan gambaran jenis gigi tiruan yang dipakai oleh responden dapt dilihat pada tabel 4.5 sebagai berikut :

Tabel 2

Distribusi frekuensi Berdasarkan pada masyarakatMenggunakan Gigi Tiruan dan Pernah Menggunakan Gigi Tiruan Di Desa Muara Bahan Tahun 2018

\begin{tabular}{cccc}
\hline No & $\begin{array}{c}\text { Pengguna } \\
\text { Gigi Tiruan }\end{array}$ & Frekuensi & $\begin{array}{c}\text { Presentase } \\
(\mathbf{\%})\end{array}$ \\
\hline 1 & $\begin{array}{c}\text { Menggunakan } \\
\text { Gigi Tiruan }\end{array}$ & 58 & 59,8 \\
\hline 2 & $\begin{array}{c}\text { Pernah } \\
\text { Menggunakan } \\
\text { Gigi Tiruan }\end{array}$ & 39 & 40,2 \\
\hline & Jumlah & $\mathbf{9 7}$ & $\mathbf{1 0 0 , 0}$ \\
\hline
\end{tabular}

Tabel 3

Distribusi Frekuensi Berdasarkan Jenis Gigi Tiruan Pada Masyarakat Di desa Muara Bahan Yang MenggunakanGigi Tiruan tahun 2018

\begin{tabular}{|c|c|c|c|}
\hline No & $\begin{array}{c}\text { Jenis } \\
\text { Gigi } \\
\text { Tiruan }\end{array}$ & Frekuensi & $\begin{array}{c}\text { Presentase } \\
\quad(\%)\end{array}$ \\
\hline 1 & $\begin{array}{c}\text { Gigi } \\
\text { Tiruan } \\
\text { Sebagian } \\
\text { Lepasan }\end{array}$ & 82 & 84,5 \\
\hline 2 & $\begin{array}{c}\text { Gigi } \\
\text { Tiruan } \\
\text { Lengkap } \\
\text { Lepasan }\end{array}$ & 10 & 10,3 \\
\hline 3 & $\begin{array}{c}\text { Gigi } \\
\text { Tiruan } \\
\text { Cekat }\end{array}$ & 5 & 5,3 \\
\hline & Jumlah & 97 & 100,0 \\
\hline
\end{tabular}

Berdasarkan tabel 3 hasil penelitian ini menunjukan bahwa dari 97 responden, mayoritas responden yang menggunakan gigi tiruan yaitu sebanyak 58 responden $(59,9 \%)$ sedngkan responden yang pernah menggunakan gigi tiruan sebanyak 39 responden (40,2\%). Dan Pada Tabel 4.3 menunjukan bahwa mayoritas responden memilih jenis gigi tiruan sebagian lepasan (GTSL), yaitu sebanyak 82 responden
$(84,5 \%)$ dan mioritas responden yang menggunakan gigi tiruan cekat (GTC) sebanyak 5 responden $(5,2 \%)$

\section{b. Kebutuhan}

Gambaran kebutuhan masyarakat di desa muara bahan yang dalam penggunaan gigi tiruan yang berjumlah 97 orang dapat dilihat pada tabel 4.6 sebagai berikut :

Tabel 4

Dristibusi Frekuensi Berdasarkan kebutuhan pada Masyarakat Di Desa Muara Bahan Dalam Pemakaian Gigi Tiruan Tahun 2018

\begin{tabular}{cccc}
\hline No & Kebutuhan & Frekuensi & $\begin{array}{c}\text { Presentase } \\
(\%)\end{array}$ \\
\hline 1 & Rendah & 15 & 15,5 \\
\hline 2 & Tinggi & 82 & 84,5 \\
\hline & Jumlah & $\mathbf{9 7}$ & $\mathbf{1 0 0 , 0}$ \\
\hline
\end{tabular}

Berdasarkan hasil penelitian ini menunjukan bahwa dari 97 orang responden, mayoritas kebutuhan responden dalam peakaian gigi tiruan tinggi yaitu berjumlah 82 responden $(84,5 \%)$ sedangkan responden yang berkebutuhan rendah berjumlah 15 responden $(15,5 \%)$

\section{c. Persepsi}

Gambaran persepsi masyarakat di desa muara bahan dalam pemakaian gigi tiruan yang berjumlah 97 orang dapat dilihat pada tabel 4.7 sebagai berikut :

Tabel 5

Distribusi Frekuensi Berdasarkan Persepsi Masyarakat Di Desa Muara bahan dalam Pemakaian Gigi Tiruan Tahun 2018

\begin{tabular}{cccc}
\hline No & Persepsi & Frekuensi & $\begin{array}{c}\text { Presentase } \\
(\%)\end{array}$ \\
\hline 1 & Negatif & 4 & 4,1 \\
\hline 2 & Positif & 93 & 95,9 \\
\hline & Jumlah & $\mathbf{9 7}$ & $\mathbf{1 0 0 , 0}$ \\
\hline
\end{tabular}

Berdasarkan hasil penelitian ini menunjukan bahwa dari 97 orang responden, mayoritas berpersepsi positif yaitu berjumlah 93 responden $(95,9 \%)$ 
sedangkan responden yang berpersepsi negatif berjumlah 4 responden $(4,1 \%)$.

\section{d. Pengetahuan}

Gambaran pengetahuan masyarakat di desa muara bahan dalam pemakaian gigi tiruan yang berjumlah 97 orang dapat dilihat pada tabel 4.8 sebagai berikut :

Tabel 6

Distribusi Frekuensi Berdasarkan pengetahuan Masyarakat Di Desa muara bahan Dalam Pemakaian Gigi Tiruan

Tahun 2018

\begin{tabular}{cccc}
\hline No & Pengetahuan & Frekuensi & $\begin{array}{c}\text { Presentase } \\
(\mathbf{\%})\end{array}$ \\
\hline 1 & Rendah & 9 & 9,3 \\
\hline 2 & Tinggi & 88 & 90,7 \\
\hline & Jumlah & $\mathbf{9 7}$ & $\mathbf{1 0 0 , 0}$ \\
\hline
\end{tabular}

Berdasarkan hasil penelitian ini menunjukan bahwa dari 97 orang responden, mayoritas berpengetahuan tinggi yaitu berjumlah 88 responden $(90,7 \%)$ sedangkan responden yang berpengetahuan rendah berjumlah 9 responden $(9,3 \%)$.

\section{e. Fasilitas Pelayanan Kesehatan}

Gambaran fasilitas pelayanan kesehatan yang menyediakan pelayanan pembuatan gigi tiruan di desa muara bahan dalam pemakaian gigi tiruan yang berjumlah 97 orang dapat dilihat pada tabel 4.3 sebagai berikut :

Tabel 7

Distribusi Frekuensi Berdasarkan Fasilitas Pelayanan Kesehatan Didesa Muara bahan Dalam Pemakaian Gigi Tiruan

Tahun 2018

\begin{tabular}{cccc}
\hline No & $\begin{array}{c}\text { Fasilitas } \\
\text { Pelayanan } \\
\text { Kesehatan }\end{array}$ & Frekuensi & $\begin{array}{c}\text { Presentase } \\
\mathbf{( \% )}\end{array}$ \\
\hline 1 & Tidak Ada & 96 & 99,0 \\
\hline 2 & Ada & 1 & 1,0 \\
\hline & Jumlah & $\mathbf{9 7}$ & $\mathbf{1 0 0 , 0}$ \\
\hline
\end{tabular}

Berdasarkan hasil penelitian ini menunjukan bahwa dari 97 orang responden, mayoritas mengatakan tidak ada pelayanan pembuatan gigi tiruan yang lengkap yaitu berjumlah 96 responden $(99,0 \%)$ sedangkan responden yang mengatakan ada pelayanan pembuatan gigi tiruan yang memiliki fasilitas lengkap berjumlah 1 responden $(1,0 \%)$

\section{PEMBAHASAN}

\section{Gigi Tiruan}

Berdasarkan tabel 3 hasil penelitian ini menunjukan bahwa dari 97 responden, responden yang menggunakan gigi tiruan yaitu sebanyak 58 responden $(59,9 \%)$. sedangkan responden yang pernah menggunakan gigi tiruan sebanyak 39 responden (40,2\%). Dan Pada Tabel 4.5 menunjukan bahwa responden memilih jenis gigi tiruan sebagian lepasan (GTSL), yaitu sebanyak 82 responden $(84,5 \%)$, dan responden yang menggunakan gigi tiruan cekat (GTC) sebanyak 5 responden $(5,2 \%)$.

Nurwahid dkk (2018) dalam penelitiannya menunjukan bahwa responden yang memakai gigi tiruan jenis GTSL sebanyak 70 orang $(86,4 \%)$ dan responden yang menggunakan gigi tiruan jenis GTP sebanyak 11 orang $(13,6 \%)$.

Dalam menggunakan gigi tiruan perlu diperhatikan bagaimana sikap untuk tetap menjaga kebersihan dan kesehatan jaringan mulut lainnya seperti membersihkan gigi tiruan secara rutin, mengeluarkan gigi tiruan dari mulut pada malam hari untuk memberikan kesempatan istirahat yang memadai kepada jaringan mulut, dan kontrol ke dokter gigi untuk konsultasi lanjutan.Salah satu faktor yang berperan yang dapat mengakibatkan perubahan-perubahan pada jaringan mulut, adalah lamanya suatu protesa dipakai didalam mulut. Karena itu banyak ahli yang menganjurkan supaya gigi tiruan tidak dipakai sepanjang siang dan malam hari secara terus menerus. Dengan demikian selaian bisa istirahat lidah maupun otot-otot di sekitar mulut dengan bantuan salivanya dapat melakukan pembersihan dan stimulasi terhadap jaringan yang berada dibawah gigi tiruan.

Gigi tiruan sebagian lepasan (GTSL) merupakan geligi tiruan yang menggantikan satu atau lebih, tetapi tidak semua gigi serta jaringan sekitarnya dan didukung oleh oleh 
gigi dan atau jaringan dibawahnya, serta dapat di keluar-masukan kedalam mulut oleh pasiennya. (Haryanto, 1991. Geligi tiruan lengkap lepasan (GTLL) yang disebut Full Denture Prosthetics atau Complete Denture Prosthetics dibuat untuk restorasi bila satu atau kedua lengkung rahang sudah tidak ada giginya lagi. (Haryanto, 1991). Gigi tiruan cekat (GTC) merupakan cabang ilmu gigi tiruan yang menyangkut pengantian dan perbaikan geligi dengan suatu pengantian tiruan yang tidak dapat dilepas dari tempatnya oleh sipemakai.(Haryanti, 1991).

Berdasarkan hasil penelitian, peneliti menyimpulkanbahwakarena selain mementingkan fungsi estetik, fungsi pengunyahan dan fungsi bicara, harga untuk pembuatan gigi tiruan sebagian lepasan lebih murah dibandingkan dengan gigi tiruan lengkap lepasan dan gigi tiruan cekat bagi mayoritas responden yang berprofesi sebagai petani.Oleh karena itu, diharapkan kepada masyarakat yang menggunakan gigi tiruan untuk tetap menjaga dan menggunakan gigi tiruan dengan benar supaya masyarakat yang berprofesi sebgai petani, IRT dapat menggunakan penghasilannya(uang) untuk memenuhi kebutuhan lainnya.

\section{Kebutuhan}

Berdasarkan hasil penelitian ini menunjukan bahwa dari 97 orang responden, mayoritas kebutuhan responden dalam peakaian gigi tiruan tinggi yaitu berjumlah 82 responden $(84,5 \%)$, sedangkan responden yang berkebutuhan rendah berjumlah 15 responden $(15,5 \%)$.

Sukini dkk (2017) dalam penelitiannya menunjukan bahwa dalam motivasi internal pada komponen kebutuhan sebesar 37 orang $(55,2 \%)$.

Kebutuhan timbul karena adanya keadaan yang tidak seimbang, tidak serasi atau rasa ketegangan yang menuntut kepuasan. Kalo sudah seimbang dan terpenuhi pemuasannya berarti tercapailah suatu kebutuhan yang diinginkan. Keadaan tak seimbang atau adanya rasa tidak puas itu, diperlukan motivasi yang tepat. Seseorang melakukan sesuatu aktivitas itu didorong oleh adanya faktor-faktor kebutuhan biologis, insting, unsur-unsur kejiwaan yang lain serta adanya pengaruh perkembangan budaya manusia. Dalam persoalan ini, Skiner lebih cenderung merumuskan dalam bentuk mekanisme hubungan stimulus dan respon yang akan memunculkan suatu aktivitas. (Sardiman, 2010)

Berdasarkan hasil penelitian, peneliti menyimpulkan bahwa, responden menyadari bahwasanya gigi tiruan dapat memberikan manfaat yang dibutuhkan seperti membaiknya fungsi estetik, fungsi pengunyahan dan memberikan rasa percaya diri.Diharapkan kepada masyarakat untuk tetap menjaga kebersihan gigi tiruan agar manfaat yang dibutuhkan dapat dirasakan dalam jangka waktu yang lama, dan mengingat bahwa untuk membuat gigi tiruan harus menempuh jarak yang terbilang jauh dan dengan biaya yang tidak sedikit pula.

\section{Persepsi}

Berdasarkan hasil penelitian ini menunjukan bahwa dari 97 orang responden, mayoritas berpersepsi positif yaitu berjumlah 93 responden $(95,9 \%)$, sedangkan responden yang berpersepsi negatif berjumlah 4 responden $(4,1 \%)$.

Sukini dkk (2015) dalam hasil penelitiannya motivasi internal menunjukan bahwa kategoro tinggi di komponen persepsi diri sebesar 46 orang $(68,7 \%)$ mempunyai persepsi yang baik.

Persepsi adalah merupakan proses menerima informasi membuat pengertian tentang dunia disekitar kita. Hal tersebut memerlukan pertimbangan informasi mana yang perlu dipperhatikan, bagaimana mengkategorikan informasi, dan bagamana menginterpretasikan dalam kerangka kerja pengetahuan kita yang sudah ada. Persepsi terjasi melalui suatu proses, dimulai ketika dorongan diterima melalui pengertian kita. Kebanyakan dorongan yang menyerang pengertian kita disaring, sisanya diorganisir dan diinterprestasikan.(Wibowo, 2013) 
Berdasarkan hasil penelitian, peneliti menyimpulkan bahwa masyarakat menggunakan gigi tiruan karena dapat meningkatkan rasa percaya diri mereka dibandingkan dengan sebelum menggunakan gigi tiruan, dan juga memberikan rasa nyaman. Dengan adanya persepsi yang benar terhadap gigi tiruan maka reponden mau menggunakan gigi tiruan.Diharapkan kepada masyarakat untuk bisa memberikan informasi mengenai pandangannya terhadap manfaat gigi tiruan kepada masyarakat lainnya yang belum menggunakan gigi tiruan meskipun sudah kehilangan banyak gigi aslinya untuk meningkatkan derajat kesehtan gigi dan mulut didasa muara bahan.

\section{Pengetahuan}

Berdasarkan hasil penelitian ini menunjukan bahwa dari 97 orang responden, mayoritas berpengetahuan tinggi yaitu berjumlah 88 responden $(90,7 \%)$, sedangkan responden yang berpengetahuan rendah berjumlah 9 responden $(9,3 \%)$.

Ira (2016) dalam penelitiannya menunjukan bahwa, responden yang berpengetahuan baik sebanyak 52 orang $(78,8 \%)$ dan responden dengan pengetahuan kurang baik sebanyak 14 orang $(21,2 \%)$.

Pengetahuan adalah segala sesuatu yang diketahui pemakai gigi tiruan. Pengetahuan adalah merupakan hasil tahu dan ini terjadi setelah orang melakukan penginderaan terhadap suatu objek tertentu. Penginderaan terjadi melalui pancaindera manusia, yakni : indera penglihatan, pendengaran, penciuman, rasa dan raba. Pengetahuan atau kognitif merupakan domain yang sangat penting untuk terbentuknya tindakan seseorang. Perilaku yang didasari oleh pengetahuan akan lebih langeng dari pada perilaku yang tidak didasari oleh pengetahuan.(swisantoro).

Penelitian ini bahwa sebagian besar tingkat pengetahuannya tinggi(90,7\%), Pengukuran tingkat pengetahuan dalam penelitian ini dilakukan melalui beberapa indikator, meliputi:, fungsi dan kegunaan gigi tiruan, cara perwatan gigi tiruandan penegtahuan tentang ahli untuk membuat gigi tiruan. Dari hasil penelitian ini diperoleh bahwa mayoritas responden memiliki tingkat pengetahuan tinggi. Pengetahuan yang diperoleh dari pengalaman sendiri atau pengalaman orang lain. Seseorang memperoleh pengetahuan bahwa gigi tiruan tidak digunakan oleh lansia saja memperoleh pengalaman melihat seorang remaja dan dewasa menggunakan gigi tiruaan. Seseorang akan membuat gigi tiruan untuk mengantikan gigi aslinya yang hilang setelah melihat lansia, remaja dan dewasa menggunakan gigi tiruan tidak susah makan karena kehilangan gigi.

Berdasarkan hasil penelitian, peneliti menyimpulkan bahwa, pengetahuan masyarakat tentang gigi tiruan baik terutama pengetahuan tentang waktu kontrol secara rutin kepada dokter gigi untuk tetap menjaga kesehatan mulut. Tetapi ada sebagian masyarakat yang tidak mengetahui apa itu gigi tiruan dan tidak merasa cemas atau prihatin mengenai masalah gusi dan gigi tiruannya.

Denganadanyasikapsepertiitudapatmempenga ruhikurangnyakesadaranmasyarakatuntukme mperhatikanakankesehatangigidanmulut, terutamakesehatangigitiruan.

Olehkarenaitudiharapkan, sebaiknyamasyarakatharusdiberikaninformasi lebihjauhdanluastentanggigitiruan,dengancara bekerjasamadengandoktergigiataupetugaskese hatangigi agar lebihmeningkatkankesehatangigidanmulutteru tamakesehatangigitiruanpadamasyarakatyang menggunakangigitiruandansudahmenggunaka ngigitiruan.

\section{Fasilitas Pelayanan Kesehatan}

Berdasarkan hasil penelitian ini menunjukan bahwa dari 97 orang responden, mayoritas mengatakan tidak ada pelayanan pembuatan gigi tiruan yang lengkap yaitu berjumlah 96 responden $(99,0 \%)$, sedangkan responden yang mengatakan ada pelayanan pembuatan gigi tiruan yang memiliki fasilitas lengkap berjumlah 1 responden $(1,0 \%)$.

Herwanda dkk (2017) dalam penelitiannya menunjukan bahwa pelayanan kesehatan donminan tergolong baik yaitu sebanyak 61 
orang $(91,0 \%)$ dan pelayanan kesehatan yang kurang baik berjumlah 1 orang $(1,5 \%)$.

Fasilitas pelayanan ksehatan adalah suatu alat atau tempat yang digunakan untuk menyelengarakan upaya pelayanan kesehatan, baik promotif, preventif, kuratif, maupun rehabilitatif yang dilakukan oleh pemerinth, pemerintah daerah, tenaga medis dan masyarakat. Fasilitas pelayanan kesehatan sangat tepat untuk pemberian informasi kesehatan, seperti ksehatan gigi dan mulut. Fasilitas kesehatan diantaranya klinik, puskesmas dan rumah sakit. (Setiawan, 2008)

Berdasarkan hasil penelitian, peneliti menyimpulkan bahwa di desa muara bahan tidak tersedia fasilitas pelayanan kesehatan seperti puskesmas dan dokter gigi. Karenanya masyarakat yang sakit harus menempuh jarak yang lumayan jauh untuk mendapatkan pengobatan begitu pula masyarakat yang ingin membuat gigi tiruan. Meskipun adanya keterbatasan fasilitas pelayanan kesehatan gigi dan mulut masyarakat desa muara bahan tidak kehilangan motivasinya untuk membuat gigi tiruan meskipun harus menemuh jarak yang jauh hanya untuk membuat gigi tiruan.Desamuarabahanmembutuhanfasilitasp elayanankesehatanterutamafasilitaspelayanan kesehatangigidanmulutdalampembuatangigitir uan. Diharapkan kepada kepala desa muara bahan untuk bekerjasama dengan tenaga kesehatan untuk mengadakan penyuluhan, sosialisasi kepada masyarakat desa muara bahan mengenai kesehatan gigi dan mulut serta pentingnya gigi tiruan untuk meningkatkan derajat kesehatan masayakat.

\section{KESIMPULAN}

Dari hasil penelitian yang diperoleh mengenai gambaran motivasi intrinsik dan ekstrinsik masyarakat dalam pemakaian gigi tiruan di desa muara bahan kabupaten kuantan singingi tahun 2018, maka dapat di ambil kesimpulan sebagai berikut:

1. Mayoritas responden berumur 26-35 berjumlah 54 orang $(55,7 \%)$, dengan jenis kelamin laaki-laki sebanyak 50 orang $(51,5 \%)$, berpendidikan SMA 30 orang
(30,9\%), dan profesi sebagai petani sebanyak 43 orang $(44,3 \%)$.

2. Dari 97 responden yang menggunakan gigi tiruansebanyak 58 orang $(59,8 \%)$, dan responden menggunakan gigi tiruan sebagian lepasan (GTSL) yaitu berjumlah 82 orang $(84,5 \%)$.

3. Tingkat kebutuhan masyarakat di desa muara bahan terhadap pemakaian gigi tiruan yaitu sebanyak 82 responden $(84,5 \%)$.

4. Tingkat Persepsi masyarakat didesa muara bahan terhadap pemakaian gigi tiruan dengan jumlah 93 responden $(95,5 \%)$.

5. Tingkat Pengetahuan masyarakat terhadap pemakaian gigi tiruan dari 97 responden yang berpengetahuan tinggi berjumlah 88 responden $(90,7 \%)$.

6. Tingkat tidak adanya fasilitas pelayanan kesehatan gigi dan mulut (gigi tiruan) di desa muara sebanyak 96 responden $(99,0 \%)$

\section{SARAN}

1. Bagi Masyarakat

Diharapkan kepada responden pengguna gigi tiruan termotivasi dalam menjaga kesehatan gigi dan mulut dan dapat memperhatiakan dampak dari kehilangan gigi.

2. Bagi Institusi Pendidikan

Diharapkan bagi institusi pendidikan dapat meningkatkan sarana prasarana dan referensi yang berkaitan dengan motivasi.

3. Bagi Tempat Peneliti

Sebagai acuan layanan kesehatan untuk mengetahui besarnya kebutuhan masyarakat terhadap pemakaian gigi tiruan dan perlu adanya fasilitas pelayanan pembuatan gigi tiruanserta melakukan sosialisasi dan penyuluhan.

4. Bagi Peneliti selanjutnya

Diharapkan melakukan penelitian lebih lanjutdengan metode yang berbeda seperti metode kualitatif, agar wawasan terhadap motivasi intrinsik dan ektrinsik masyarakat dalam pemakaian gigi tiruan menjadi lebih luas.

\section{DAFTAR PUSTAKA}


Aprilia P. (2014). Motivasi Masyarakat Terhadap Pemakaian Gigi Tiruan Di Dusun II Desa Batu Belah Kabupaten Kampar Tahun 2014. KTI tidak diterbitkan. Program D III Teknik Gigi, Pekanbaru.

Haryanto, Dkk. (1991). Ilmu Geligi Tiruan Sebagian Lepasan. Jakarta: Hipokrates

Islamuddin, H. (2012). Psikologi Pendidikan. Yogyakarta: Pustaka Pelajar.

Notoatmodjo, S. (2010). Ilmu Perilaku Kesehatan. Jakarta: Rineka Cipta.

Notoatmodjo, S. (2010). Promosi Kesehatan Teori dan Aplikasi. Jakarta: Rineka Cipta

Notoatmodjo, S. (2005). Metodologi Penelitian Kesehatan. Jakarta

Noor. J. (2013). Penelitian Ilmu Manajemen Tinjauan Filosofis dan praktis. Jakarta: Prenadamedia Group.

Nur. A. (2016). Gambaran Perilaku Masyaraka Tentang Pemakaian Gigi Tiruan Di Desa Mayang Ponkai Kecamatan Kampar Kiri Tengah Kabupaten Kampar Tahun 2016. KTI tidak diterbitkan. Program D III Teknik Gigi, Pekanbaru.

Nurwahid, Dkk. (2018). Pengaruh Motivasi Ekstrinsik Terhadap tingkat Kepatuhan Pemakai Gigi Tiruan Lepasan Di Kelurahan Batu Kota. (Online) (http://www.google.co.id/search=gambaran $\underline{+ \text { motivasi) }}$

Prasetyawati, A.E. (2011). Ilmu Kesehatan Masyarakat Untuk Kebidanan Holistik. Yogyakarta: Nuha Medika.

Prawira. P.A. (2016). Psikologi Pendidikan Dalam Perspektif Baru. Jogjakarta: Ar-ruzz Mesia.

Sanjaya,W. (2009). Kurikulum dan Pembelajaran: Teori dan Praktik Pengembangan Kurikulum Tingkat Satuan Pendidikan (KTSP). Jakarta: Kencana Prenada Media Group.

Sardiman, A.M. (2010). Interaksi dan Motivasi Belajar Mengajar. Jakarta: Rajawali Pers.

Saryono. (2010). Metodologi Penelitian Kesehatan. Jogjakarta: Mitra Cendekia Press

Setiawati, S. (2008). Proses Pembelajaran dalam Pendidikan Kesehatan. Jakarta: Trans Info Media.

Sumantri, S. (2012). Perilaku Organisasi. Universitas Padjadjaran.
Sukini, Dkk. (2015). Motivasi Internal dan Eksternal Pemakaian Gigi Tiruan pada Lansia, (Online), Vol. 11, No. 3, (http://www.google.co.id/search?motivasi $+\mathrm{i}$ ntrinsik + kstrinsik + dalam + pemakaian + gigi $+\mathrm{t}$ iruan)

Swistantoro. (2004). Sosial Budaya dan Perilaku Kesehatan. Pekanbaru. 